\title{
LIPOPOLYSACCHARIDE MEDIATED REGULATION OF NEUROENDOCRINE ASSOCIATED PROPROTEIN CONVERTASES AND NEUROPEPTIDE PRECURSOR PROCESSING IN THE RAT SPLEEN.
}

\author{
Guillaume Lansac $^{1}$, Weijia Dong ${ }^{2}$, Claire M. Dubois ${ }^{3}$, Nadia BenLarbi ${ }^{4}$, Carlos Afonso ${ }^{5}$, Isabelle \\ Fournier ${ }^{4}$, Michel Salzet ${ }^{4}$ and Robert Day ${ }^{1}$
}

From the Département de ${ }^{1}$ Pharmacologie et ${ }^{3}$ Service d'Immunologie, Faculté de médecine, Université de Sherbrooke, Sherbrooke, Québec, J1H 5N4, Canada, ${ }^{2}$ Neuroscience Research Group, University of Calgary, Calgary, Alberta, T2N 1N4, Canada, ${ }^{4}$ Laboratoire de Neuroimmunologie des Annélides, UMR CNRS 8017, Université des Sciences et Technologies de Lille, 59650 Villeneuve d'Ascq, France and ${ }^{5}$ Laboratoire de Chimie Structurale Organique et Biologique, UMR CNRS 7613, Batiment F, BP 45, Université Pierre et Marie Curie, 4 place Jussieu, 75005 Paris Cédex 5.

\section{Running title : Lipopolysaccharide induction of convertases in spleen}

Address correspondence to: Robert Day, Département de Pharmacologie, Institut de Pharmacologie de Sherbrooke, Faculté de Médecine, Université de Sherbrooke, 3001, $12^{\mathrm{e}}$ Ave. Nord, Sherbrooke, Québec, J1H 5N4, Canada; Tel. (819) 564-5428; Fax. (819) 564-5400; E-mail: robert.day@ usherbrooke.ca

Within the secretory pathway, the family of proprotein convertases cleave inactive precursors at paired basic residues to generate a myriad of biologically active peptides. Within the PC family, PC1/3 and PC2 are well known for their preferential expression within neuroendocrine cells. However, various data now indicate their potential expression in immune cells. The aim of our study was two fold: (1) survey PC expression in immune tissues, with emphasis on PC1/3 and PC2 and (2) examine PC expression under conditions that mimic an infectious state using lipopolysaccharide, known to activate immune cells via Toll-like receptors. Spatial and temporal analysis of tissues from control and lipopolysaccharide treated rats were carried out using in situ hybridization histochemistry, Northern blot, mass spectrometry and antibacterial assays. Our tissue survey showed the basal expression of all PCs in the lymph nodes, thymus and spleen including $\mathrm{PC} 1 / 3$ and PC2. Focusing on the spleen, basal expression of $\mathrm{PC1} / 3$ was seen in the $\mathrm{red} \mathrm{pulp} / \mathrm{marginal}$ zone areas, suggesting expression within macrophages. Lipopolysaccharide treatment produced significant changes in PC1/3 expression and notably an induction in $B$ lymphocytes within germinal centers. Similarly, PC2, which was undetectable in control spleens, was induced in germinal centers following lipopolysaccharide treatment. The PC1/3 and PC2 substrate proenkephalin was also induced following lipopolysaccharide treatment in the marginal zone, where $\mathrm{PC} 1 / 3$ expression was also found. Mass spectrometry analysis of spleen extracts demonstrated the presence of the antibacterial peptide enkelytin. Our studies confirmed that $\mathrm{PC} 1 / 3$ and $\mathrm{PC} 2$ expression was not restricted to neurons and endocrine cells, but was also found under basal conditions in both macrophage and lymphocytes. Additionally, plasticity of PC expression in immune cells was observed under conditions that miminc pathogen-like infections, suggesting a mechanistic link through Toll-like receptors. Collectively, these data clearly implicate PCs in immune responses, both innate and acquired.

Proteolytic processing is a posttranslational modification by which a cell diversifies and regulates the protein products of its genes. In mammalian species, a family of enzymes known as the subtilisin-like proprotein convertases $(\mathrm{PCs})^{1}$ participates in the formation of biologically 
active products through their endoproteolytic actions (for a review see Ref. 1). Cleavage by PCs occurs at single and paired basic residues of precursor proteins and is recognized as an essential step to yield active hormones and neuropeptides. The PC family of enzymes consists of seven distinct members named, furin, PC2, PC1/3, PC4, PACE4, PC5/6 and PC7 (1). The distribution pattern of each $\mathrm{PC}$ has been extensively investigated, mainly in brain, heart, endocrine tissues and reproductive organs (1-4). Some of these enzymes, such as furin, PC5/6 and PC7 have a ubiquitous or widespread tissue distribution (4-6). In contrast, PC2 and PC $1 / 3$ have an expression pattern that closely follows that of endocrine and neuronal cells $(2,7)$. This is consistent with the notion that PC2 and PC1/3 process precursors that enter the regulated secretory pathway, mainly hormones and neuropeptides (8). One insight obtained from distribution studies is that although distinct expression patterns are observed for each PC, it is clear that cells do not express only one PC at a time, but rather express a distinct cocktail of PCs (1-4).

The expression of neuropeptides was originally believed to be exclusively associated with endocrine and nervous tissues (9). However, it is now known that expression of various neuropeptide precursors, such as proopiomelanocortin (POMC) (10,11), proenkephalin (PENK) (12-14) and endomorphins (15), known to be processed by PCs, is not limited to the neuroendocrine system, and has been demonstrated in various cells of the immune system. Mature forms of the expected neuropeptides have been isolated and characterized in immunocytes, such as peptides with immunoregulatory and signaling functions (16-18). Recent studies have shown that neuropeptide precursors can also yield peptides with antibacterial activities (19-23). For example, two PENK-derived peptides with antibacterial activity, enkelytin and peptide B, have been shown to be produced by the immune system after a bacterial challenge $(19,22,24)$. The processing of the neuroendocrine-associated precursors such as chromogranins $\mathrm{A}$ and $\mathrm{B}$ can also result in the release of antibacterial peptides, vasostatin-1 (20) and secretolytin (21). Chromogranins A and B, more commonly viewed as markers for endocrine and neuronal cells, were also found to have an immune origin (22). The sum of these data lead us to the hypothesis that the same processing enzymes which cleave these substrates in endocrine and neural tissues could also be expressed in immunocytes.

At present, the few studies that have investigated PCs expression in the immune system have focused on isolated cells. PC1/3 expression has been shown in a human monocyte cell line $(25)$ or in differentiated macrophages $(13,25)$ whereas PC2 was detected in polymorphonuclear leukocytes (13). Recently, PC1/3 and PC2 expression have been demonstrated in rat immunocytes of the blood and within inflamed tissue (26). While these studies showed expression of PCs, they did not give much indication as to the potential roles of PCs in immune function. Little is known about PC activity in immune effectors organs, such as spleen, thymus and lymph nodes. In order to provide insights as to PCs functions in immune cells, we focused on two specific aims. First, we determined the in vivo expression pattern of PCs mRNA within tissues of the immune system under resting conditions. Secondly, we mimicked bacterial like infection conditions by using lipopolysaccharide (LPS), a pathogenassociated molecular pattern (PAMP) ligand acting through toll-like receptor 4 (TLR4) (27), and examined PCs expression and PENK, as well as antibacterial activity. The data showed that PCs expression is highly regulated in immune cells following LPS challenge and demonstrated the need for precursor processing in immune defense mechanisms.

\section{MATERIALS AND METHODS}

Animal and tissue preparation - Adult male Wistar rats (250-300 g; Charles River, St Constant, Qc, Canada) were used throughout the experiments. Rats ( $\mathrm{n}=3 /$ experiments $)$ were injected intraperitonally with either LPS serotype 055:B5 (Sigma, St Louis, MO) at dose of $150 \mu \mathrm{g} / 100 \mathrm{~g}$ or saline for control. Rats were killed by decapitation, tissues (mesenterial lymph nodes, lung, thymus and spleen) were rapidly removed and frozen in 2-methylbutane pre-cooled to $-35^{\circ} \mathrm{C}$. All procedures were conducted in accordance with 
the guidelines of the Medical Research Council of Canada. The extracted tissues were stored at $80^{\circ} \mathrm{C}$ until cryo-sectioning. Frozen $10 \mu \mathrm{m}$ sections ( $n=100 /$ tissue) were cut on a Reichert cryostat (Leica Corp., Depew, NY), thaw-mounted on polylysine-coated glass slides and stored at $-80^{\circ} \mathrm{C}$ until further processing.

cRNA probes synthesis - All experiments carried out in these studies used antisense cRNA probes and sense probes for negative control. Probes were synthesized by in vitro transcription of linearized plasmid DNA and labeling was done by incorporation of radioactive $\left[{ }^{35} \mathrm{~S}\right] \mathrm{UTP} /\left[{ }^{35} \mathrm{~S}\right] \mathrm{CTP}$ (Amersham Pharmacia Biotech, Arlington Heights, IL) (2). All probes used have been described before : furin (4), PC2 (28), PC1/3 (29), PACE4 (30), PC5/6 (6), PC7 (5) and PENK (31).

In situ hybridization - The in situ hybridization studies were carried out using antisense and sense labeled cRNA probes with $\left[{ }^{35} \mathrm{~S}\right] \mathrm{UTP} /\left[{ }^{35} \mathrm{~S}\right] \mathrm{CTP}$ labeled cRNA probes. Radioactive probes were diluted to $33 \times 10^{3} \mathrm{dpm} / \mu \mathrm{l}$. Following hybridization with PCs or PENK probes, the sections were submitted to standard in situ hybridization procedures (2) followed by x-ray autoradiography for 3-7 days, resulting in low resolution images. These slides were also dipped in NTB2 emulsion (Eastman Kodak Co. Rochester, NY) to obtain cellular resolution. The sections hybridized were counterstained with cresyl violet, cleared in xylene, and mounted with Permount histological mounting medium (Fisher Scientific, Pittsburgh, PA).

Northern blot analysis - Total RNA was extracted from tissues using a guanidium isothiocyanate methodology, which includes a lithium chloride precipitation step (2). The RNA (5 $\mu \mathrm{g})$ was separated on an agarose gel containing 6\% formaldehyde and blotted on Nytran Plus membranes (Schleicher \& Schuell, Inc., Keene, $\mathrm{NH})$. Prehybridization was carried out for 2 hours at $65^{\circ} \mathrm{C}$ in hybridization buffer containing $5 \%$ SDS, $0.4 \mathrm{M}$ sodium phosphate buffer, $1 \mathrm{mM}$ EDTA, $1 \mathrm{mg} / \mathrm{mL}$ BSA and $50 \%$ formamide. The purified $\left[{ }^{32} \mathrm{P}\right]$ UTP-labeled cRNA probe was then added to the prehybridization buffer and incubated with the Nitran membrane overnight at $65^{\circ} \mathrm{C}$.
Filters were washed in $0.1 \mathrm{X}$ sodium citrate, $0.1 \%$ SDS, $1 \mathrm{mM}$ EDTA at $72^{\circ} \mathrm{C}$ for 2 hours and exposed to $\mathrm{X}$-ray film (XAR-5 film with intensifying screens; Eastman Kodak Co.) at $-80^{\circ} \mathrm{C}$ for 48 hours.

Polyclonal antisera - Polyclonal anti-enkephalins (Met-EnkRF, Met-Enk RGL, Leu-Enk) used in dot immunobinding assay (DIA) were kindly provided by Iris Lindberg (New Orleans, USA). The specificity of the antisera has been described (3234).

Antibacterial assays - The antibacterial activity was tested by liquid growth inhibition assay as described by Bulet et al (35). Briefly, $10 \mu \mathrm{L}$ of the interest product was incubated in microtiter plates with $100 \mu \mathrm{L}$ of a mid-logarithmic phase culture of Micrococcus luteus (strain A270) or E coli (strain D31) with a starting absorbance of $0.001\left(1.2 \times 10^{6}\right.$ cells $/ \mathrm{ml}$ ) at $620 \mathrm{~nm}$ in poor broth medium. Microbial growth was assessed by the increase in A620 nm after a 16 hours incubation at $30^{\circ} \mathrm{C}$ for $M$ luteus and $37^{\circ} \mathrm{C}$ for $E$ coli.

Dot immunobinding assay (DIA) - The 40\% acetonitrile (ACN) reversed-phase HPLC (RPHPLC) eluted fractions were freeze dried before resuspending in $100 \mu \mathrm{L}$ of water. The procedure was conducted according to Salzet et al (36). One microliter of the $100 \mu \mathrm{L}$ total solution was spotted onto a nitrocellulose membrane and was incubated with the enkephalin antisera (1/1000). Bound antibodies were detected by a goat anti-rabbit $\mathrm{IgG}$ conjugated to horseradish peroxidase by using a chemoluminescence kit (ECL; Amersham, Saclay, France).

Purification procedure - Frozen rat spleens from control or injected animals were individually submitted to acidic extraction (acetic acid 1N: 20 $\mathrm{mL}$ for $5 \mathrm{~g}$ of tissue) before sonification and bath under gentle stirring overnight at $4^{\circ} \mathrm{C}$. Centrifugation $\left(10000 \mathrm{~g}, 30\right.$ minutes, $\left.4^{\circ} \mathrm{C}\right)$ was then used to clarify supernatants, which were loaded onto 2 g Sep-Pak C18 Vac cartridges (Waters Inc) equilibrated in water acidified with $0.05 \%$ of trifluroracetic acid (TFA). After washing with acidified water, three successive elution steps were performed with $10 \%, 40 \%$ and $80 \% \mathrm{ACN}$ in acidified water. The obtained fractions were then 
concentrated by evaporation and reconstituted in respectively $100 \mu \mathrm{L}, 500 \mu \mathrm{L}$ and $1 \mathrm{~mL}$ of pure water (depending on the material quantity) for the $10 \%, 40 \%$ and $80 \%$ ACN fractions. $10 \mu \mathrm{L}$ were tested for antimicrobial activity as described above. Only $40 \%$ fractions were active and submitted to RP-HPLC. All the HPLC steps were carried out on a Beckman Gold HPLC system equipped with a Beckman 168 photodiode array detector. Column effluent was monitored by UV absorption at $220 \mathrm{~nm}$ and $280 \mathrm{~nm}$. Aliquots of the $40 \%$ Sep-Pak fractions were subjected to reversed phase HPLC on a Ultasphere C18 column $(250 \mathrm{x}$ $4.6 \mathrm{~mm}$, Macherey Nagel). Elution was performed with a linear gradient of $0-60 \% \mathrm{ACN}$ in acidified water $(0.5 \% \mathrm{TFA})$ over 60 minutes at a flow rate of $0.5 \mathrm{~mL} /$ minute. Fractions corresponding to absorbance peaks were collected in polypropylene tubes, dried, reconstituted in water and tested for antimicrobial activity and antibody recognition by DIA before analysed in mass spectrometry.

Characterization procedure - Samples were analyzed using $\alpha$-cyano-4-hydroxycinnamic acid (HCCA) as matrix. To get a better homogeneity of the dried samples and thus a better spot to spot reproducibility during the analyses, two layers preparation was chosen for the MALDI experiments. Briefly, $1 \mathrm{~mL}$ of HCCA in acetone $(15 \mathrm{mg} / \mathrm{mL})$ was applied on the MALDI target. After evaporation and preparation of a thin layer of matrix, $1 \mathrm{~mL}$ of samples and immediately after $1 \mathrm{~mL}$ of classical HCCA solution (10 mg in TFA $0.1 \% / \mathrm{ACN} 3: 7, \mathrm{v} / \mathrm{v}$ ) were applied on top of the first layer and allow to dry at room temperature. Analyses were carried out on a Voyager Elite (Persceptive BioSystems, Framingham, MA) MALDI-time of flight mass spectrometer equipped with a $\mathrm{N}_{2}$ laser ( $2 \mathrm{~ns}$ pulse duration, $2 \mathrm{~Hz}$ repetition rate). Mass spectra were recorded in the positive linear mode using delayed extraction. Laser fluence was set at a value just above the threshold for ion production. Calibration was realized with four external calibrants covering the mass range of interest (Substance P, ACTH 18-39, ACTH 7-38 and bovine insulin) prepared in the same way as the samples.

HPLC fractions recognized by the antibodies or presenting an antibacterial activity are of special interest for this study and corresponding mass spectra were more carefully looked out for these fractions. In order to unambiguously identify the differentially expressed peptides, structural information was collected through $\mathrm{MS}^{\mathrm{n}}$ fragmentation studies using ESI-Ion trap instrument. The experiments were performed on an Esquire 3000 instrument (Bruker Gmbh, Bremen, Germany) running in the nanospray mode. To obtain more or less charged ions, two different solvents were used for ESI. The analyte was directly mixed with an equal ratio of $\mathrm{ACN}$ or with an equal ratio of formic acid $1 \%$ in $\mathrm{ACN} .3$ $\mathrm{mL}$ of the mixture was then loaded into the nanospray silver coated needle (Protana). To get a stable spray the capillary voltage was generally set between 750-800 V. The different parameters of the instrument were set to obtain the best intensity for the interesting ions. For $\mathrm{MS}^{2}$ experiments, helium was the collision gas and the energy was set in a range from $0.9 \mathrm{~V}$ to $1.5 \mathrm{~V}$ depending on the mass and the charge of the ion. All the collected data were treated using the software integrated to the instrument.

\section{RESULTS}

Basal Expression of PCs in the Lung, Lymph Nodes and Thymus - We first conducted a survey of PCs mRNA expression patterns in immune related tissues using in situ hybridization. Different expression patterns were observed for each PC, except for PC4, that we could not detect any kind of expression, consistent with its preferential expression in testicular germ cells (37). All further studies thus exclude PC4. For the other PCs, we observed a widespread and complex distribution in immune related tissues (Fig 1). In agreement with its previously described ubiquitous distribution (4), furin was highly expressed in the cortex and medulla of mesenterial lymph nodes (Fig 1A). The cortex is characterized by a dense accumulation of lymphocytes. The medulla consists of lymphatic tissue cords interspersed with sinuses. While the expression of furin was less abundant in the follicles, it was still detectable in this zone. Numerous lymphocyte subpopulations populate the lymph nodes and furin expression represents an important component in all these cell types. In the thymus (Fig 1B), high levels of furin gene expression were observed both in the cortex and medulla, although slightly higher in the cortex. The thymic cortex 
contains numerous densely packed lymphocytes without forming lymphatic nodules. In contrast, the medulla contains fewer lymphocytes but more epithelial reticular cells. The thymus is a site of $\mathrm{T}$ cell differentiation and high levels of furin expression imply it potentially important role. The observed variations in furin expression levels were consistent with previous observations in other tissues $(3,4)$.

$\mathrm{PC} 1 / 3$ and PC2 have been considered as neuroendocrine-specific convertases, since they are preferentially expressed in neurons and endocrine cells. In the present study we observed PC2 mRNA expression in lymph nodes follicles (Fig 1C and D), which contain densely packed lymphocytes, mainly lymphoblasts and B lymphocytes (38). PC1/3 was also expressed in the lymph nodes, in scattered cells within the dense paracortical regions, where scattered macrophages are normally found (Fig 1E). Consistent with this observation, PC1/3 expression in the lung (Fig 1F) was seen in alveolar walls, a localization indicative of free macrophages.

PC5/6 and PC7 were surveyed in the lymph nodes and the thymus. High levels of PC5/6 transcripts were observed in the cells lining lymph nodes sinuses (Fig $1 \mathrm{H}$ ). High PC7 mRNA levels were in the lymph node follicles (Fig 1I) and in the thymus with an identical distribution pattern to that of furin (Fig $1 \mathrm{~J}$ and $1 \mathrm{~A}$ ).

PC mRNA Regulation in the Spleen - In Fig 2 are representative sections of a comparative distribution of PCs mRNAs in the rat spleen. Furin, PC1/3, PACE4, and PC5/6 mRNAs (Figs $2 \mathrm{~A}, \mathrm{C}, \mathrm{D}$ and $\mathrm{E}$, respectively) were expressed in the red pulp (39), a highly heterogeneous compartment consisting of extravasated blood cells including macrophages, some lymphocytes, a spongy framework of reticular cells, arterial capillaries and a vast system of venous sinuses. Consistent with the known ubiquitous expression of furin mRNA (4), its expression in the white pulp (WP) was also noted, although at much lower levels. No PC2 expression was observed in the spleen under static conditions (Fig 2B). In agreement with previous studies showing high levels of PC7 in lymphoid-associated tissues $(1,5)$; PC7 mRNA was highly expressed distributed in the white pulp of spleen, a compartment containing macrophages, reticular dendritic cells, lymphocytes and lymphoblasts (Fig 2F).

In order to mimic an infectious state, we used a bacterial-like challenge by treating rats with a single dose of LPS. In this context of immune system activation, we focused on the effects on PC 2 and $\mathrm{PC} 1 / 3$ gene expression in the spleen at 3 , 6, 9 and 12 hours post-injection. General markers of macrophages (CD14) and B cells (CD20) were also examined under the same conditions. Regional differences in the spleen were analyzed and included WP, germinal centers (GC), periarteriolar lymphocyte sheath (PALS), marginal zone (MZ) and RP. Representative sections showing the effects of LPS on PC2 and PC1/3 expression in the spleen are shown in Figs 3-6. The sum of these data are summarized in Table 1.

In the spleen of control animals, PC1/3 mRNA was principally expressed in the RP (Fig 3A) and this localization pattern, although more restricted, was very similar to that of CD14 (Fig 3B). CD14 expression was found almost equally in the RP and $\mathrm{MZ}$, while PC1/3 was found more predominantly in the RP (Table 1). This data suggests the expression of $\mathrm{PC} 1 / 3$ within RP macrophages. Following 6 hours of LPS treatment (Fig 3C), $\mathrm{PC} 1 / 3$ expression was still observed in the RP areas, but was now more widely distributed to include the MZ, in a pattern that was almost identical to that of CD14. At the $6 \mathrm{~h}$ time point, CD14 mRNA expression and distribution was unchanged as compared to the control (Fig 3D compared to 3B). Dramatic changes in $\mathrm{PC} 1 / 3$ expression were observed at the $9 \mathrm{~h}$ time point (Fig $3 \mathrm{E})$. In addition to the $\mathrm{RP} / \mathrm{MZ}$ distribution, $\mathrm{PC} 1 / 3$ mRNA expression was now observed within the GC (Fig 3E), a densely packed compartment situated in the middle of the WP characterized by active lymphocyte production and containing few macrophages. At this time point CD14 expression was still unchanged (Fig 3F). Finally, at the 12h time point (Fig 3G), PC1/3 expression had a completely different pattern from its initial distribution seen in the controls (Fig 3A). The strongest $\mathrm{PC} 1 / 3$ expression was observed within the GC region of the WP, with a sharp decrease in $\mathrm{RP}$ areas. This pattern was also in sharp contrast to 
the unchanged CD14 pattern seen after 12h LPS treatment (Fig 3H).

A similar time course analysis was carried out for PC2 in the spleen. In Fig 4 are shown the representative sections of that study, focusing on the major changes observed at the $12 \mathrm{~h}$ time point. As previously mentioned, no PC2 expression could be detected in spleens of control animals (Fig 4A). Following 12h of LPS treatment (Fig 4C), PC2 expression could be detected in the WP areas, suggesting an expression pattern within the GC. This expression pattern was compared to that of CD20, a B cell marker (Fig 4B and 4 D). As expected, in control sections, CD20 was principally expressed in the white pulp areas, including the GC, but not the PALS. CD20 expression was also observed the MZ (see Table 1). Following LPS treatment, CD20 mRNA was increased in the GC area, but decreased in the $\mathrm{MZ}$ area, resulting in the modified pattern observed in Fig 4D. This expected observation most likely reflects the re-distribution of $\mathrm{B}$ cells that responds to $\mathrm{T}$ cell-independent II antigen, such as LPS. A strong similarity between PC2 expression and the new CD20 expression pattern was noted (Fig 4C and 4D).

The observed distribution of PC1/3, PC2, CD14 and CD20 mRNAs was further examined in emulsion dipped adjacent sections to confirm the regional and cellular expression patterns. In Fig $5 \mathrm{~A}, \mathrm{PC} 1 / 3 \mathrm{mRNA}$ was found mainly in the RP, with few PC1/3 expressing cells in the MZ or the GC. Following a $12 \mathrm{~h}$ treatment of LPS (Fig 5B), $\mathrm{PC} 1 / 3$ expression changed dramatically, with the highest levels being observed in the GC, followed by the MZ. As for PC2, no signal was observed in control sections (Fig 5C), but a distinct signal was observed in the GC after LPS treatment (Fig 5D). Spleen sections labeled from control (Fig 5E) and treated rats (Fig 5F) showed a re-distribution pattern for CD20 mRNA. Control sections express $\mathrm{CD} 20$ in the $\mathrm{MZ}$ and $\mathrm{GC}$, while sections from treated animals express CD20 mRNA mainly in the GC. The GC expression pattern of CD20 (Fig $5 \mathrm{~F}$ ) corresponded to that observed for $\mathrm{PC} 1 / 3$ (Fig 5B) and PC2 (Fig 5D) after 12h LPS treatment. Sections labeled for CD14 mRNA are also shown in Fig 5G and 5H. The CD14 mRNA expression pattern was unchanged after LPS treatment, with a positive signal being observed in the RP and MZ.

LPS-induction of Proenkephalin in the Spleen We then examined the spleen expression patterns of potential PC substrates in the same animal model (Fig 6). We focused on PENK since previous studies have shown its expression in immune cells, including neutrophils, lymphocytes and macrophages $(12-14,19)$. Furthermore, recent studies have also demonstrated that antibacterial activities could be derived from the C-terminal processing of PENK (23). Under basal condition, no detectable expression of the PENK mRNA could be observed by in situ hybridization (Fig 6A). However, PENK expression was strongly upregulated in our model of bacterial infection (Fig 6B, C and D). After 12 hours of LPS treatment, PENK was expressed in scattered cells of a distinct spleen compartment, the marginal zone (MZ) (Fig 6C and D). Since PENK mRNA has a very restricted expression pattern, this increased expression was easily confirmed by Northern blot analysis (Fig 6F). As expected, the PENK band was observed at $1.4 \mathrm{~kb}$.

Proenkephalin Processing in the Spleen - We then examined PENK derived peptides in the spleen of control and LPS treated rats, in order to establish whether antibacterial forms previously reported $(19,23,24,40,41)$ could be observed. Peptide extracts were prepared from control spleens and spleens from LPS treated rats. The extracts were pre-purified by sep-pak and HPLC separation on a C18 column. The obtained fractions were subjected to a rigorous analysis that included three steps: 1) antimicrobial test, 2) DIA tests with PENK antibodies and 3) MALDI analysis of the positive fractions of step 1 and 2. Using antibodies directed against Met-Enk RGL and Leu-Enk, immunoreactivity was observed in fractions eluting from the column at $29 \%$ acetonitrile of control and LPS samples. Additionally, immunoreactivity was also observed in fractions eluting at $34 \%$ acetonitrile of LPS samples and presented a high antibacterial activity compared to control. The MALDI-MS analyses of these fractions between both conditions are shown in Figs 7 and 8 . 
In the $29 \%$ fraction, a mass at a $\mathrm{m} / \mathrm{z} 1214.67$ was detected in control (Fig. 7A) and stimulated animals (Fig 7B) that corresponds to oxidized YGGFM(O)RRVGR peptide, whereas its non oxidized form YGGFMRRVGR (m/z 1198.54) was only detected in injected animals. Masses of $\mathrm{m} / \mathrm{z}$ of 840.39 and 1154.93 were found in both control (Fig 7A) and injected (Fig 7B) animals and corresponded to YGGFLKR peptide and YGGFMRRVG, respectively (Table 1). We also included an inset (Fig 7C and D) to show average mass of the peptides corresponding to YGGFMRRVG.

The $34 \%$ fraction, shown in Fig $8 \mathrm{~A}$ and $8 \mathrm{~B}$, was immunoreactive with the anti-Met-EnkRF and anti-Met-Enk antibodies. This fraction had only weak antibacterial activity in the controls (Fig 8A) and a high activity in challenged animals (Fig 8B). Analysis of these fractions showed masses at 3346.1 , 3384.0, 3491.6 corresponded to $\mathrm{MH}^{+}$ oxidized enkelytin, $\mathrm{MK}^{+}$oxidized enkelytin, and $\mathrm{MH}^{+}$diphosphorylated enkelytin. An enlargement of this group of mass is shown in Fig 8C and 8D. From the control animals, (Fig 8C) masses at 3331.6 and 3368.02 corresponding to $\mathrm{MH}^{+}$ enkelytin and $\mathrm{MNa}^{+}$oxidized enkelytin at lower levels. These observed masses are in agreement with a previous analysis carried out to identify the different forms of the C-terminal proenkephalin derived peptides $(23,24)$. Following LPS injection (Fig 8D), the enkelytin levels of diphosphorylated forms greatly increased whereas the oxidized forms decreased. We observed masses at 3331.6, $3346.1,3442.59,3491.6$ correpsonding to $\mathrm{MH}^{+}$ enkelytin, $\mathrm{MH}^{+}$oxidized enkelytin, $\mathrm{MH}^{+}$ dioxidized monophosphorylated enkelytin and $\mathrm{MH}^{+}$diphosphorylated enkelytin. Furthermore, the mass at 3342.59 corresponding to $\mathrm{MH}+$ deoxidized monophosphorylated was observed only in the challenged animals. It is noted that $\mathrm{MH}^{+}$enkelytin greatly increased in LPS animals as well as $\mathrm{MH}^{+}$diphosphorylated enkelytin. These results are in agreement with the high antibacterial activity found in the $34 \%$ fraction of LPS injected animals. The diphosphorylated enkelytin forms have previously been shown to have highly antibacterial activity (24) (Table 1). These data support previous studies in chromaffin granules, bovine infectious fluids and human plasma after coronary cardiology bypass, where all the different forms of enkelytin were detected $(19,23,24)$.

\section{DISCUSSION}

The neuroendocrine cells secrete their products in a regulated manner, in response to a specific stimulus. The expression of markers such as neuropeptides, chromogranins and neuropeptide processing enzymes $\mathrm{PC} 2$ and $\mathrm{PC} 1 / 3$ was thought to be restricted to the neuroendocrine system. However, neuropeptide expression has been found elsewhere than in neurons or endocrine cells such as in tumor cells (42), cardiomyocytes (43), and immune cells $(16,17,26,44,45)$. The unexpected distribution of PENK seen in this study, as well as the presence in immune cells of several so-called markers of neuroendocrine system such as chromogranins (22) and opioids peptides derived from PENK and POMC (16-18,26) lead us to suggest that immune cells are capable of cellular plasticity such that they can potentially express a neuroendocrine phenotype. This also leads us to ask the question if the full complement of processing enzymes are co-expressed with these neuroendocrine precursors in immune cells.

The PC family has been shown to be important in the activation of neuropeptides. The present study demonstrated that PCs with ubiquitous or widespread distribution such as furin, PC5/6 and PC7 are present in various cells of the immune system. While any PC could potentially generate neuropeptides, most of our attention has been focused on PC1/3 and PC2. These two enzymes are considered excellent markers of neuroendocrine cells (1). Surprisingly, we observed in the spleen PC1/3 mRNA under basal condition and up-regulation of both $\mathrm{PC} 1 / 3$ and PC2 mRNA following a pathogen-like infection. Regulation of PC1/3 and PC2 mRNAs levels are not surprising in endocrine systems, as they have been shown to be modulated under a variety of conditions, such as glucocorticoids, dopaminergic or thyroid hormone manipulations (2). These effects are all mediated through appropriate receptor-signaling pathways of the target endocrine cells. In contrast, modulations of $\mathrm{PC} 1 / 3$ and PC2 expressions are not well understood in immune cells. LPS mimics pathogen-like infection through its interaction with TLR4. TLRs are a 
family of receptors that contact the environment and provide specific sensing for an important component of the innate immunity (27). TLRs are found on immune cells and recognize specific microbial molecular patterns. The activation of these sentinel molecules leads to a process of intracellular signaling through to transcriptional control that culminates with an array of host immune responses. Therefore, TLRs play an important part in the innate immune recognition of invading pathogens, initiating immune responses characterized by the release of pro-inflammatory cytokines and interferons via transcription factors such as NFkB and IRF3. From our data, we can surmise that these signaling pathways/transcriptional factors also modulate/induce PC1/3 and PC2 in immune cells as well as one of their target substrates, namely PENK. One potential function of this powerful modulatory process is to produce antibacterial peptides such as enkelytin. Since PC1/3 and PC2 are processing enzymes for many precursors, a number of other important functions could also be uncovered, directly related to innate and even acquired immunity.

The induction of PENK gene expression within the spleen MZ following LPS induction and its processing into antibacterial peptides is not surprising as this compartment is harboring spleen sinuses, weakly assembled lymphocytes, plasmocytes and macrophages. Indeed, terminal branches of the arterial system discharge their content between the cells of the MZ so that it offers a good opportunity for cells to meet systemic antigens arriving in the spleen. In fact, lymphocytes crossing this frontier meet several reticular dendritic cells which are able to present antigens on their surface to the immunocompetent lymphocytes exactly in the same manner that macrophages do during the immune reaction. MZ immunocytes form then a first line of defense against systemic invaders where antibacterial peptides might play a critical role. The secondary response is very fast and the spleen becomes the organ that produces the most important amount of antibodies of the organism.

Our results demonstrate that bacterial-like challenge can result in very impressive and dynamic levels of induction of PCs in the spleen.
Such striking modulation supports the notion that the system is mounting a response where PCs play an important role. PC regulation/induction could result in the differential and temporal processing of PENK. As the spleen is intimately implicated in blood filtration and because treatment conditions such as LPS can alter the sub-regional distribution of immune cells, changes in PCs and PENK mRNA expression could partly be explained by redistribution, infiltration or migration of some immune cells. However, the concept of cellular traffic cannot entirely explain the changes seen in mRNA expression following LPS injection for PC2 and PC1/3. In fact, as shown in Fig 5, and following LPS treatment, $\mathrm{PC} 1 / 3$ and $\mathrm{PC} 2$ are strongly expressed in the germinal centers, which are very rich in CD20, a B lymphocyte marker.

The biochemical data confirm the presence of PENK derived peptides in spleen and with a processing similar to what is occurring in the central nervous system. In fact, the four enkephalin peptides (YGGFMRRVGR, YGGFMRRVG, YGGFLKR and enkelytin) found are the ones present at the C-terminal part of the rat PENK. Moreover, these four peptides must derive from PCs action and most likely PC2 and/or $P C 1 / 3$. For the peptide YGGFMRRVGR, only PC2 can act due to the sequence RXXR $\$ P$ where the $\mathrm{P} 1$ ' is a Pro, as previously shown in dynorphin 1-17 to yield dynorphin 1-8 (46). Furthermore, after LPS treatment, this peptide is overexpressed like PC2 and the antibacterial peptide enkelytin. This is in line with the data we previously demonstrated in monocytes during interleukin-6 stimulation (22). PENK processing after immune response stimulation allows the production of the antibacterial peptide enkelytin which is found in phagolysosomes (22) whereas Met-Enk, Met-Enk $\mathrm{RF}$ are released in order to stimulate chemotaxis (19) and act as cytokines (47). It is also interestingly to note that in non-stimulated animals, the oxidized forms of enkephalin derived peptides are high compared to injected animals. This indicates that oxidation could be an inactivating process for enkephalins as previously shown for FMRFamide peptides family (48).

As in the neuroendocrine system, processing might be essential in immune cells to generate different biologically active neuropeptides 
depending on the function required. For example, PENK could be cleaved by a combination of PCs shortly after LPS induction resulting in the production of short peptides such as Met-Enk-ArgPhe and the antibacterial peptide enkelytin as observed in our study. Therefore, differential PCs expression in immune cells might be an important mechanism by which defense activities are modulated. However, the fact that PENK derived peptides such as YGGFMRRVG, YGGFLKR and YGGFM(O)RRVGR are detected in the spleen of non-infected animals could also reflect a bifunctional role of these peptides independently of the infection and thus could have a role in cell to cell communication/modulation.

Differential processing of PENK by the PCs appears to generate multiple biological activities in immune cells. The opioid Met-Enk and its analogs, through their delta opioid receptor activities can enhance the immune reaction by stimulating immunocyte chemotaxis, phagocytosis and secretion of immunostimulatory factors, but would also mediate an analgesic effect in peripheral inflamed tissues $(18,47,49,50)$. Furthermore, the release of enkelytin and Met-Enk peptides is increased in different cases such as LPS injection, surgical trauma or bacterial exposure $(19,24)$. These data suggest that the coprocessing and co-liberation of enkelytin and MetEnk peptides could represent a unified neuroimmune protective response to an immediate threat to the organism, regardless of the specific stimulus. According to this hypothesis, enkelytin would be released to deal immediately with the microbial threat, thus allowing time for the opioid peptides simultaneously liberated from PENK to stimulate, activate or recruit immunocytes. This hypothesis is further supported by the presence of specific opioid receptors on immunocytes (51). This unified mechanism could represent an important survival strategy.

PCs most likely have numerous and uncharacterized functions in the immune system, as they could play a role in protein processing necessary for classically defined immune cell functions such as immunoglobulins, cytokines and chemokines production. Furthermore, the important spatial and temporal changes observed in PC expression following pathogen-like challenge provide strong evidence that they are implicated not only in the innate immune response but also in the initiation of the adaptive immune response. The strong upregulation of $\mathrm{PC} 2$ and $\mathrm{PC} 1 / 3$ in the white pulp is of particular interest, as this could mean that other proneuropeptides might be expressed and processed within lymphocytes. Taken together, these results, in agreement with previous reports $(26,52-54)$, allow us to add PCs to the growing numbers of endocrine markers expressed by immune cells and point to a significant role in the immune response mechanisms. 


\section{REFERENCES}

1. $\quad$ Bergeron, F., Leduc, R., and Day, R. (2000) J Mol Endocrinol 24(1), 1-22

2. Day, R., Schafer, M. K., Watson, S. J., Chretien, M., and Seidah, N. G. (1992) Mol Endocrinol 6(3), 485-497

3. Schafer, M. K., Day, R., Cullinan, W. E., Chretien, M., Seidah, N. G., and Watson, S. J. (1993) J Neurosci 13(3), 1258-1279

4. Day, R., Schafer, M. K., Cullinan, W. E., Watson, S. J., Chretien, M., and Seidah, N. G. (1993) Neurosci Lett 149(1), 27-30

5. Seidah, N. G., Hamelin, J., Mamarbachi, M., Dong, W., Tardos, H., Mbikay, M., Chretien, M., and Day, R. (1996) Proc Natl Acad Sci U S A 93(8), 3388-3393

6. Lusson, J., Vieau, D., Hamelin, J., Day, R., Chretien, M., and Seidah, N. G. (1993) Proc Natl Acad Sci U S A 90(14), 6691-6695

7. Seidah, N. G., Gaspar, L., Mion, P., Marcinkiewicz, M., Mbikay, M., and Chretien, M. (1990) DNA Cell Biol 9(10), 789

8. $\quad$ Steiner, D. F. (1998) Curr Opin Chem Biol 2(1), 31-39

9. $\quad$ Douglass, J., Civelli, O., and Herbert, E. (1984) Annu Rev Biochem 53, 665-715

10. Oates, E. L., Allaway, G. P., Armstrong, G. R., Boyajian, R. A., Kehrl, J. H., and Prabhakar, B. S. (1988) J Biol Chem 263(21), 10041-10044

11. Mechanick, J. I., Levin, N., Roberts, J. L., and Autelitano, D. J. (1992) Endocrinology 131(1), 518-525

12. Rosen, H., Behar, O., Abramsky, O., and Ovadia, H. (1989) J Immunol 143(11), 3703-3707

13. Vindrola, O., Mayer, A. M., Citera, G., Spitzer, J. A., and Espinoza, L. R. (1994) Neuropeptides 27(4), 235-244

14. Martin, J., Prystowsky, M. B., and Angeletti, R. H. (1987) J Neurosci Res 18(1), 82-87

15. Jessop, D. S., Major, G. N., Coventry, T. L., Kaye, S. J., Fulford, A. J., Harbuz, M. S., and De Bree, F. M. (2000) J Neuroimmunol 106(1-2), 53-59

16. Weigent, D. A., and Blalock, J. E. (1997) Chem Immunol 69, 1-30

17. Blalock, J. E. (1985) Clin Endocrinol (Oxf) 22(6), 823-827

18. Stefano, G. B., Scharrer, B., Smith, E. M., Hughes, T. K., Jr., Magazine, H. I., Bilfinger, T. V., Hartman, A. R., Fricchione, G. L., Liu, Y., and Makman, M. H. (1996) Crit Rev Immunol 16(2), 109-144

19. Tasiemski, A., Salzet, M., Benson, H., Fricchione, G. L., Bilfinger, T. V., Goumon, Y., MetzBoutigue, M. H., Aunis, D., and Stefano, G. B. (2000) J Neuroimmunol 109(2), 228-235

20. Lugardon, K., Raffner, R., Goumon, Y., Corti, A., Delmas, A., Bulet, P., Aunis, D., and MetzBoutigue, M. H. (2000) J Biol Chem 275(15), 10745-10753

21. Strub, J. M., Garcia-Sablone, P., Lonning, K., Taupenot, L., Hubert, P., Van Dorsselaer, A., Aunis, D., and Metz-Boutigue, M. H. (1995) Eur J Biochem 229(2), 356-368

22. Tasiemski, A., Hammad, H., Vandenbulcke, F., Breton, C., Bilfinger, T. J., Pestel, J., and Salzet, M. (2002) Blood 100(2), 553-559

23. Goumon, Y., Strub, J. M., Moniatte, M., Nullans, G., Poteur, L., Hubert, P., Van Dorsselaer, A., Aunis, D., and Metz-Boutigue, M. H. (1996) Eur J Biochem 235(3), 516-525

24. Goumon, Y., Lugardon, K., Kieffer, B., Lefevre, J. F., Van Dorsselaer, A., Aunis, D., and MetzBoutigue, M. H. (1998) J Biol Chem 273(45), 29847-29856

25. LaMendola, J., Martin, S. K., and Steiner, D. F. (1997) FEBS Lett 404(1), 19-22 
26. Mousa, S. A., Shakibaei, M., Sitte, N., Schafer, M., and Stein, C. (2004) Endocrinology 145(3), 1331-1341

27. Pasare, C., and Medzhitov, R. (2005) Adv Exp Med Biol 560, 11-18

28. Seidah, N. G., Chretien, M., and Day, R. (1994) Biochimie 76(3-4), 197-209

29. Lanoue, E., and Day, R. (2001) Endocrinology 142(9), 4141-4149

30. Dong, W., Marcinkiewicz, M., Vieau, D., Chretien, M., Seidah, N. G., and Day, R. (1995) J Neurosci 15(3 Pt 1), 1778-1796

31. Schafer, M. K., Day, R., Ortega, M. R., Akil, H., and Watson, S. J. (1990) Neuroendocrinology 51(4), 444-448

32. $\quad$ Lindberg, I., and Dahl, J. L. (1981) J Neurochem 36(2), 506-512

33. Lindberg, I., and White, L. (1986) Arch Biochem Biophys 245(1), 1-7

34. Lindberg, I., and Thomas, G. (1990) Endocrinology 126(1), 480-487

35. Bulet, P., Cociancich, S., Dimarcq, J. L., Lambert, J., Reichhart, J. M., Hoffmann, D., Hetru, C., and Hoffmann, J. A. (1991) J Biol Chem 266(36), 24520-24525

36. Salzet, M., Bulet, P., Wattez, C., and Malecha, J. (1994) Eur J Biochem 221(1), 269-275

37. Seidah, N. G., Day, R., Hamelin, J., Gaspar, A., Collard, M. W., and Chretien, M. (1992) Mol Endocrinol 6(10), 1559-1570

38. De Wolf-Peeters, C., and Delabie, J. (1993) Semin Oncol 20(6), 555-569

39. Sharp, B. M., Roy, S., and Bidlack, J. M. (1998) J Neuroimmunol 83(1-2), 45-56.

40. Metz-Boutigue, M. H., Goumon, Y., Lugardon, K., Strub, J. M., and Aunis, D. (1998) Cell Mol Neurobiol 18(2), 249-266

41. Salzet, M., and Tasiemski, A. (2001) Dev Comp Immunol 25(3), 177-185

42. Moody, T. W., Chan, D., Fahrenkrug, J., and Jensen, R. T. (2003) Curr Pharm Des 9(6), 495-509

43. Springhorn, J. P., and Claycomb, W. C. (1989) Biochem J 258(1), 73-78

44. Przewlocki, R., Hassan, A. H., Lason, W., Epplen, C., Herz, A., and Stein, C. (1992) Neuroscience 48(2), 491-500

45. Behar, O., Ovadia, H., Polakiewicz, R. D., and Rosen, H. (1994) Endocrinology 134(1), 475-481

46. Day, R., Lazure, C., Basak, A., Boudreault, A., Limperis, P., Dong, W., and Lindberg, I. (1998) J Biol Chem 273(2), 829-836

47. Plotnikoff, N. P., Faith, R. E., Murgo, A. J., Herberman, R. B., and Good, R. A. (1997) Clin Immunol Immunopathol 82(2), 93-101

48. Salzet, M., Wattez, C., Verger-Bocquet, M., Beauvillain, J. C., and Malecha, J. (1993) Brain Res 601(1-2), 173-184

49. Kamphuis, S., Eriksson, F., Kavelaars, A., Zijlstra, J., van de Pol, M., Kuis, W., and Heijnen, C. J. (1998) J Neuroimmunol 84(1), 53-60

50. Stein, C., Hassan, A. H., Lehrberger, K., Giefing, J., and Yassouridis, A. (1993) Lancet 342(8867), 321-324

51. Bidlack, J. M. (2000) Clin Diagn Lab Immunol 7(5), 719-723.

52. Salzet, M., Vieau, D., and Day, R. (2000) Trends Neurosci 23(11), 550-555.

53. Day, R., and Salzet, M. (2002) Neuroendocrinol Lett 23(5-6), 447-451

54. Salzet, M. (2002) Neuroendocrinol Lett 23(1), 8-9

\section{FOOTNOTES}

* We would like to thank Dr. Iris Lindberg (Louisiana State University) for providing the enkephalin antibodies. We also wish to thank Ms Xue Wen Yuan for technical support. This work was supported by grants from the Canadian Institutes of Health Research (CIHR; to R.D.) and The Arthritis Society (to R.D. and C.M.D.), the Centre National de la Recherche Scientifique (C.N.R.S.), Ministère de l'Education Nationale, de la Recherche et des Technologies (MENRT), the Génopole of Lille and the Fondation de la 
Recherche Médicale (To I.F.). G.L. is a recipient of postgraduate scholarship from the Natural Sciences and Engineering Research Council of Canada (NSERC).

1 The abbreviations used are: PC, proprotein convertase; POMC, proopiomelanocortin; PENK, proenkephalin; LPS, lipopolysaccharide; PAMPs, pathogen-associated molecular patterns; TLR, toll-like receptor; BSA, bovine serum albumin; DIA, dot immunobinding assay; ACN, acetonitrile; RP-HPLC, reverse phase-high pressure liquid chormatography; TFA, trifluroracetic acid; HCCA, $\alpha$-cyano-4hydroxycinnamic acid; MALDI, matrix-assisted laser desorption/ionization; ACTH; adrenocorticotropic hormone; RP, red pulp; WP, white pulp; GC, germinal centers; PALS, periarteriolar lymphocyte sheath; $\mathrm{MZ}$, marginal zone; kb, kilobase

\section{FIGURE LEGENDS}

Fig. 1. Distribution of PCs in rat immune related tissues by in situ hybridization. Low power autoradiographic $\mathrm{x}$-ray (A, B, C, E, I and J) and cellular resolution (D, F, G and H) images showing furin (A and B), PC2 (C, D and E), PC1/3 (F and G), PC5/6 (H) and PC7 (I and J) mRNA expression in various tissues. (D) Higher magnification of PC2 expression in the follicles of mesenterial lymph nodes. The emulsion-dipped sections of lymph nodes (F) and lung $(\mathrm{G})$ revealed labeling of PC1/3 respectively in the follicles or on the walls of the alveoli (arrows). In the lymph nodes (H), PC5/6 transcripts were localized along the walls of the sinuses. (E) No positive labeling was observed in control section labeled with PC2 sense probe. LN, lymph nodes, C, cortex; F, follicles; M, medulla. Bar, 4mm.

Fig. 2. Comparative distribution of $\mathrm{PCs}$ in rat spleen. Autoradiograms showing distribution of mRNA coding for (A) furin, (B) PC2, (C) PC1/3, (D) PACE4, (E) PC5/6 and (F) PC7 in the spleen. RP, red pulp; WP, white pulp. Bar, $4 \mathrm{~mm}$.

Fig. 3. Induction of $P C 1 / 3$ mRNA expression by LPS in rat spleen. Autoradiograms showing distribution of mRNA coding for PC1/3(A, C, E and G) and CD14 (B, D, F and H) in the rat spleen. (A) PC1/3 expression in control spleen had a similar distribution to the macrophage marker CD14 (B). In (C, E and $\mathrm{G}$ ) is the time course of PC1/3 mRNA expression of rats treated with LPS for 6,9 and 12 hours, respectively. Note that the pattern of $\mathrm{PC} 1 / 3$ expression changed from mainly in the red pulp to that of the white pulp. (D, F and H) No change in CD14 mRNA labeling was seen following LPS treatment. WP, white pulp; RP, red pulp. Bar, $6 \mathrm{~mm}$.

Fig. 4. Induction of PC2 mRNA expression by LPS in rat spleen. PC2 and CD20 mRNA distribution as revealed by in situ hybridization in spleens of (A and C) control and (B and D) LPS treated rats. Twelve hours after LPS administration, PC2 mRNA expression was induced in the germinal center of the white pulp (B), in a similar distribution than the B cell marker CD20 (D). (C) In control animals, CD20 expression was seen in the white pulp, but not in the germinal centers. GC, germinal center; WP, white pulp. Bar, $6 \mathrm{~mm}$.

Fig. 5. Regional changes observed in PCs mRNA expression and CD14 and CD20 markers, before and after LPS. In A, C, E and D are adjacent spleen sections of control rats showing the normal distribution pattern of (A) PC1/3, (B) PC2, (C) CD20 and (D) CD14. In B, D, F, and $\mathrm{H}$ are distribution of (B) PC1/3, (D) PC2, (F) CD20 and (H) CD14 after LPS treatment, also on adjacent sections. PC1/3 is normal expressed in the red pulp, however after LPS treatment is found in the GC and MZ, while the CD14 marker is very poorly expressed in the GC. PC2 mRNA is induced after LPS and is observed solely in the $\mathrm{GC}$ where CD20 is strongly expressed.

Fig. 6. Induction of PENK mRNA expression by LPS in rat spleen. Autoradiographic (A, B, C and E) and cellular resolution (D) images showing PENK mRNA distribution in spleen. (A) PENK mRNA 
expression was undetectable in the spleen of control animals. Increased expression levels were observed after (B) 6 and (C) 12 hours following LPS injection. (D) The cells labeled after 12 hours were located in the marginal zone. (E) No positive labeling was observed in control sections labeled with PENK sense probe. (F) Increased PENK mRNA levels were observed by Northern blot analysis. Corresponding 18S ribosomal analysis determined that equal loading of each lane was obtained (data not shown). Molecular weight markers are shown on the right. WP, white pulp; Mz, marginal zone. Bar, $6 \mathrm{~mm}$.

Fig. 7. MALDI-time of flight mass spectra of HPLC fractions eluted at $29 \%$ ACN. (A) Control (saline solution injection) and (B) challenged animals (LPS injection) were analysed. M/z at 840.39, 1154.93, and 1214.67 correspond to YGGFLKR, YGGFMRRVG, oxidized YGGFM(O)RRVGR, respectively were observed in controls. However, in the challenged animals (B) an additional peptide with $\mathrm{m} / \mathrm{z}$ at 1198.54 corresponding to YGGFMRRVGR was observed, the non-oxidized form of the latter peptide. (C) and (D) are enlargements of the YGGFMRRVG peak in (A) control and (B) in LPS challenged animals, respectively. In (C) an unidentified group of masses of 1143.721144 .83 and 1145.74 are absent in injected rats. However, the peaks at $1154.89,1155.87$ and 1156.78 are present in the controls and correspond to average mass of the peptide YGGFMRRVG.

Fig. 8. MALDI-time of flight mass spectra of HPLC fractions eluted at $34 \%$ ACN. (A) Control animals and (B) LPS injected animals. In (A) masses at 3346.1, 3384.0 and 3491.6 correspond to respectively $\mathrm{MH}^{+}$oxidized enkelytin. $\mathrm{MK}^{+}$oxidized enkelytin and the $\mathrm{MH}^{+}$diphosophorylated enkelytin. In (B) $\mathrm{m} / \mathrm{z}$ 3331.6, 3346.1 3442.59, 3491.6 correspond to respectively $\mathrm{MH}^{+}$enkelytin, $\mathrm{MH}^{+}$oxidized enkelytin, $\mathrm{MH}^{+}$ dioxidized monophosphorylated enkelytin, $\mathrm{MH}^{+}$diphosphorylated enkleytin. In (A) and (B) the group of masses at 1673.3 correspond to $\mathrm{MH}^{2+}$ oxidized enkelytin. (C) and (D) are the enlargements of the group of peaks at 3346.1 scanned between 3100 and 3800 . 
Table 1. Summary of observed changes in PC2, PC1/3, CD20 AND CD14 in regional areas of the spleen after LPS treatment.

\begin{tabular}{|c|c|c|c|c|}
\hline & GC & PALS & MZ & RP \\
\hline CD20 Control & ++ & - & +++ & + \\
\hline $3 \mathrm{~h}$ & +++ & - & ++ & + \\
\hline $6 \mathrm{~h}$ & ++++ & - & - & + \\
\hline $9 \mathrm{~h}$ & +++++ & - & + & + \\
\hline $12 \mathrm{~h}$ & +++++ & - & + & + \\
\hline & & & & \\
\hline CD 14 Control & - & - & ++ & ++ \\
\hline $6 \mathrm{~h}$ & - & - & +++ & +++ \\
\hline $12 \mathrm{~h}$ & $+*$ & $+*$ & +++ & +++ \\
\hline & - & - & & + \\
\hline PC1/3 Control & - & - & + & ++++ \\
\hline $3 \mathrm{~h}$ & - & - & + & ++ \\
\hline $6 \mathrm{~h}$ & + & - & + & ++ \\
\hline $9 \mathrm{~h}$ & - & + & + & + \\
\hline $12 \mathrm{~h}$ & - & - & & \\
\hline & & - & - & - \\
\hline PC2 Control & - & - & - & - \\
\hline $12 \mathrm{~h}$ & - & - & - \\
\hline & - & - & & + \\
\hline PENK Control & - & - & + & + \\
\hline
\end{tabular}

* Indicates scattered cells. 
Table 2 : PENK derived peptides detected in control and in injected animals from fractions 29\% and 34\% ACN. (Phospho: Phosphorylated, $\mathrm{Na}+$ and $\mathrm{K}+$ are added ions, O: oxidized). A (+) indicates detection of the peptide form, without regard to the levels of that peptide.

\begin{tabular}{|l|l|l|l|l|}
\hline Peptide & \multicolumn{3}{|l|}{ Fractions 29\% } & \multicolumn{2}{l|}{ Fractions 34\% } \\
\hline & Control & Injected & Control & Injected \\
\hline YGGFLMR & + & + & & \\
\hline YGGFMRRVG & + & + & & \\
\hline YGGFM(O)RRVGR & + & + & & \\
\hline YGGFMRRVGR & & + & & \\
\hline Enkelytin & & & + & + \\
\hline$($ O)Enkelytin & & & + & + \\
\hline (O) Na+ Enkelytin & & & + & + \\
\hline (O) K+ Enkelytin & & & + & + \\
\hline $\begin{array}{l}\text { Di(O)monophospho } \\
\text { Enkelytin }\end{array}$ & & & & + \\
\hline Diphospho Enk & & & + & + \\
\hline
\end{tabular}




\section{FIGURE 1}

\section{A \\ $\mathbf{L N}$}
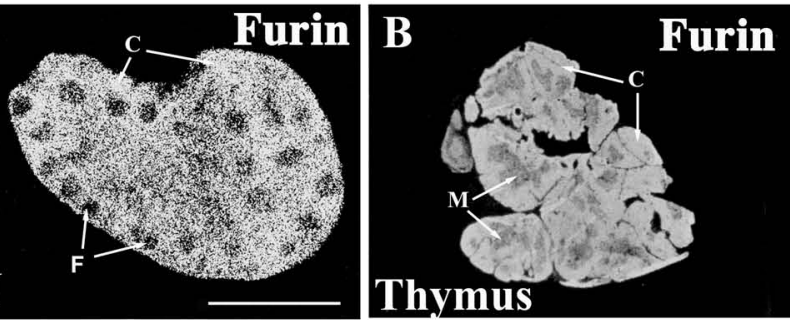

C

PC2 D

PC2

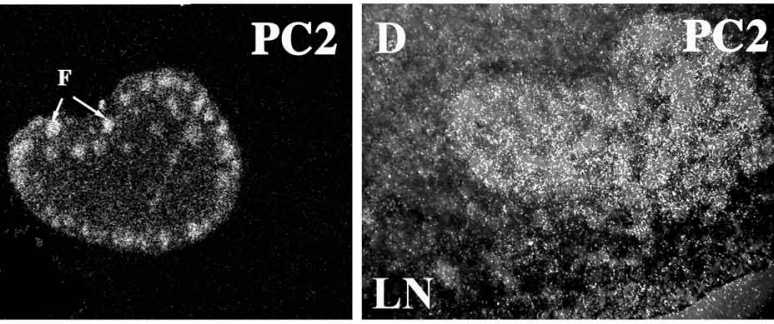

$\mathbf{L N}$

E

LN

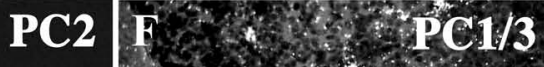

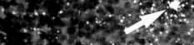
$\therefore$.

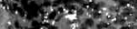

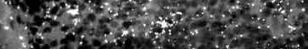

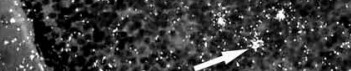
Sense LN \% W tho C. PC1/3 H/67, : PC5/6 I $t^{2}+1 t^{2}$

I

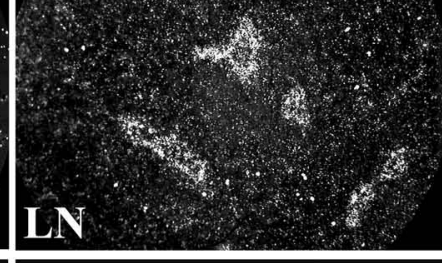
(3) LN

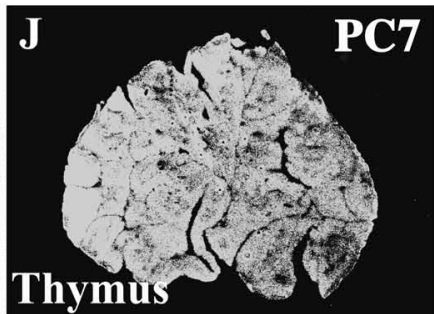



Figure 3

$\mathbf{A}$

PC1/3 B

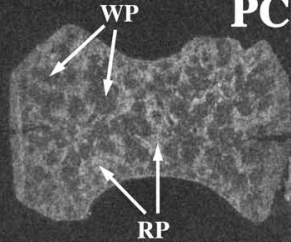

Control

Control

C

PC1/3 D

CD14

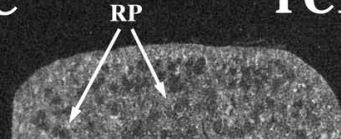

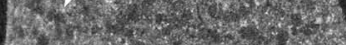

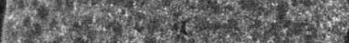

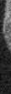

$6 h$

$6 h$

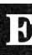

\section{PC1/3 F}

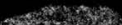

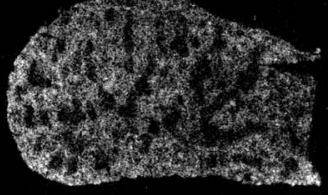

CD14

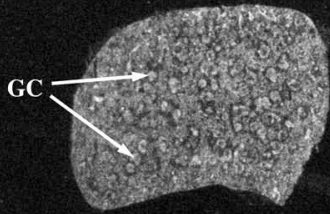

9h

9h

G

\section{PC1/3 H}

CD14

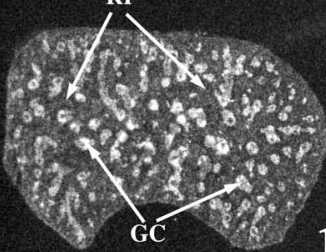

$12 \mathrm{~h}$

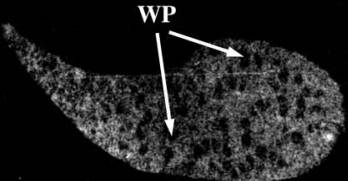




\section{Figure 4}

$\mathbf{A}$

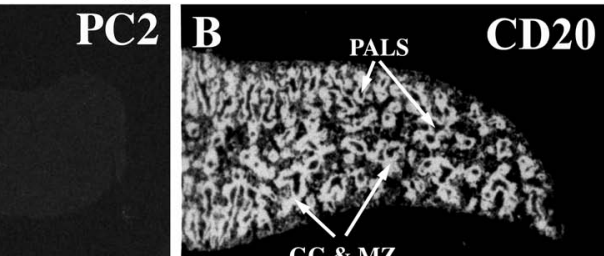

Control

GC \& MZ

Control

C

\section{PC2 D}

CD20

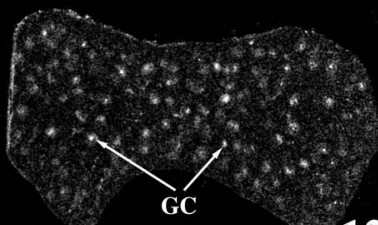

$12 \mathrm{~h}$

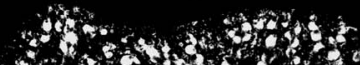

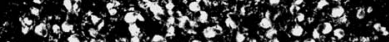

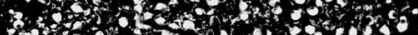

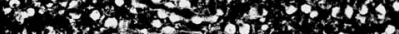

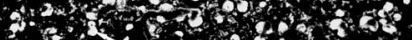

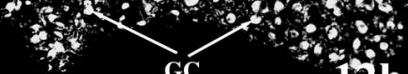
$12 \mathrm{~h}$ 


\section{FIGURE 5}

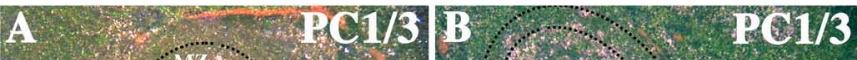
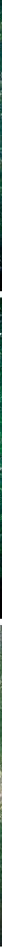

\section{CD14 II}

GC

RP

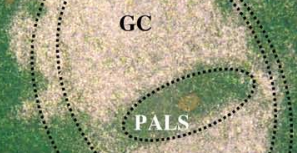

3 


\section{Figure 6}

A

Control B

$6 h$
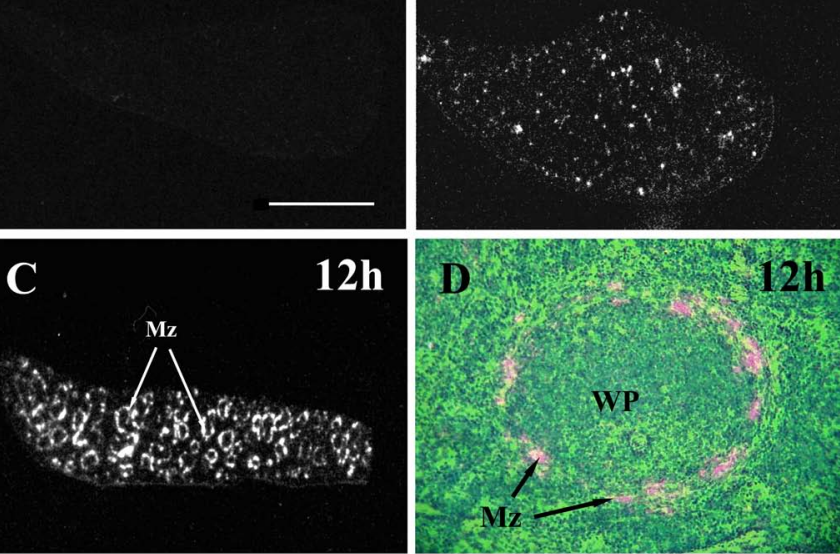

E

Sense

F

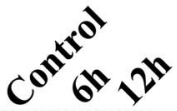

- 1.4 kb 


\section{FIGURE 7}
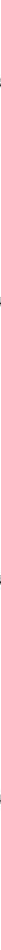


\section{FIGURE 8}
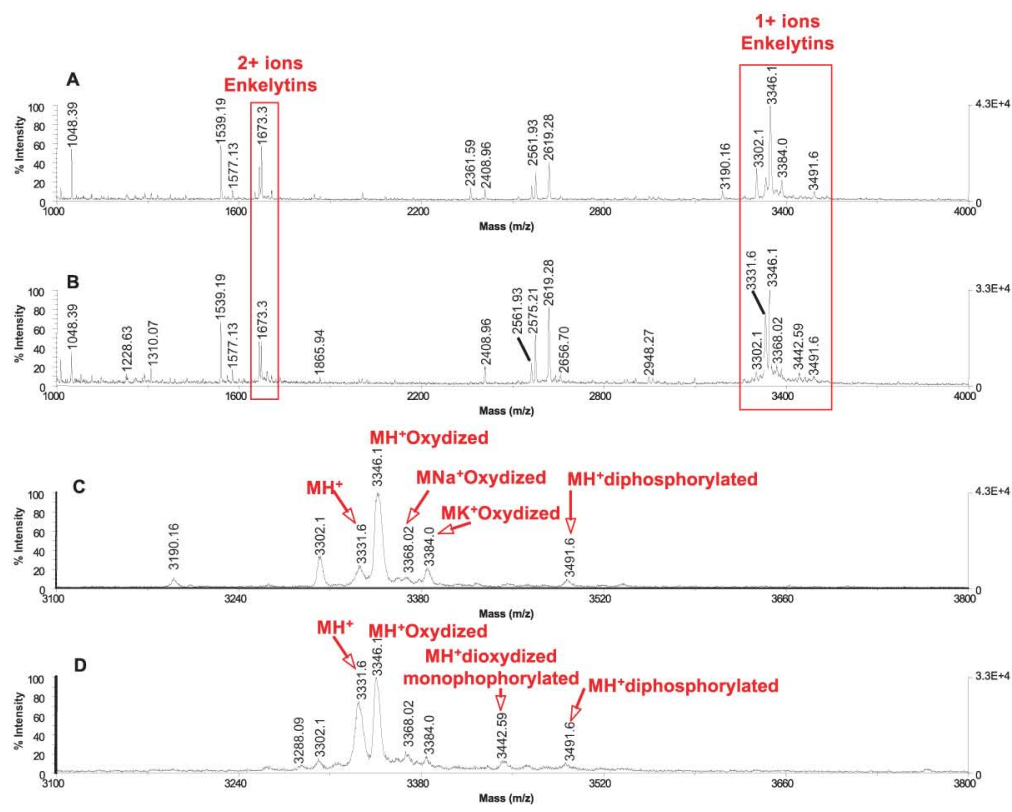